\section{Commentary: The esophagectomy cake finally may be ready for its icing}

\author{
Evan T. Alicuben, MD, ${ }^{a}$ and Anthony W. Kim, $\mathrm{MD}^{\mathrm{b}}$
}

Complications related to the anastomosis of the gastric conduit to the proximal esophagus remain the Achilles heel of esophagectomy, contributing to its notorious reputation as an operation with considerable morbidity. Many adjuncts aimed at decreasing their incidence have been investigated. ${ }^{1,2}$ In their novel study published in this issue of the Journal, Takeda and colleagues ${ }^{3}$ push the envelope even farther through their development, description, and validation of a supercharged cervical anastomosis for esophagectomy (SAFE) by providing augmented arterial inflow and venous outflow of the gastric conduit. Given the technical challenges of this operation, as well as the relative paucity of literature characterizing perfusion analysis techniques, their efforts should be lauded.

This important study has 2 noteworthy findings. First, following creation of a gastric conduit, surgeons face the challenge of assessing perfusion to the distal conduit to determine an optimal area for anastomosis. Although most use general inspection and possibly Doppler ultrasound of the gastroepiploic artery, Zehetner and colleagues ${ }^{1}$ described the use of laser-assisted dye angiography for use in qualitatively assessing graft perfusion. In their study, Takeda and colleagues use SPY-Q technology (Novadaq Technologies, Toronto, Ontario, Canada) to quantitatively assess perfusion at different time points and various stages of arterial and venous clamping. By carefully defining baseline perfusion ratios and their reference to venous drainage

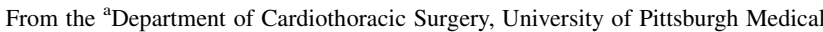
Center, Pittsburgh, $\mathrm{Pa}$ and ${ }^{\mathrm{b}}$ Division of Thoracic Surgery, Keck School of Medicine, University of Southern California, Los Angeles, Calif.

Disclosures: The authors reported no conflicts of interest.

The Journal policy requires editors and reviewers to disclose conflicts of interest and to decline handling or reviewing manuscripts for which they may have a conflict of interest. The editors and reviewers of this article have no conflicts of interest.

Received for publication July 1, 2020; revisions received July 1, 2020; accepted for publication July 2, 2020; available ahead of print July 11, 2020.

Address for reprints: Anthony W. Kim, MD, 1510 San Pablo St, Suite 514, Division of Thoracic Surgery, Keck School of Medicine, University of Southern California, Los Angeles, CA 90033 (E-mail: anthony.kim@med.usc.edu).

J Thorac Cardiovasc Surg 2021;162:698-9 0022-5223/ $\$ 36.00$

Copyright $₫ 2020$ Published by Elsevier Inc. on behalf of The American Association for Thoracic Surgery

https://doi.org/10.1016/j.jtcvs.2020.07.009

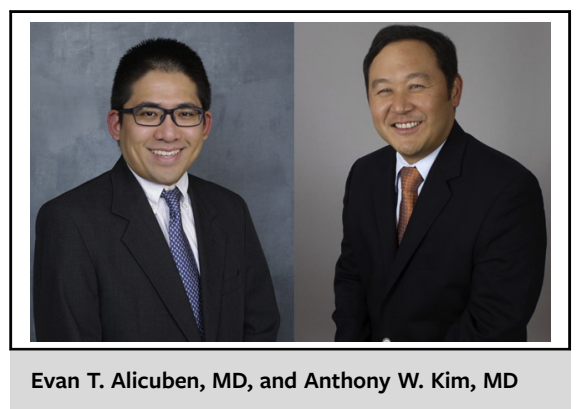

CENTRAL MESSAGE

The reduction in cervical anastomotic complications achieved

by supercharging the gastric

conduit may prove to be the much-desired icing on the legendary cake that thoracic surgeons want to have and eat.

and arterial inflow (superdrainage and supercharge ratios, respectively), the authors have established a replicable system that will greatly assist other surgeons in their pursuit of performing what can be a daunting aspect of the reconstitution of the foregut.

Second, the authors were able to demonstrate significant differences in perfusion, initially with a $5 \%$ increase in augmented venous outflow and then considerably higher with a $73 \%$ increase in additional arterial inflow. These findings corresponded to their observed differences in anastomotic leak rates: $10.9 \%$ in the non-SAFE group and a remarkable $0 \%$ fistula rate in the SAFE group. This difference persisted long-term with an anastomotic stenosis rate of $14.5 \%$ in the non-SAFE group and $4 \%$ in the SAFE group.

These results provide promising potential for improvements in postoperative complications following esophagectomy. It is notable that the differences in complication rates did not meet statistical significance, possibly secondary to a relatively small sample size. In addition, whether the supercharging procedure was performed was based primarily on the availability of a plastic surgeon, and thus patient selection was not standardized. Both shortcomings could be addressed with a randomized trial powered to detect such differences. This study provides ample foundation for embarking on such a study.

Perhaps most importantly, optimal patient selection for this significant procedure remains unknown. Although a 
subset of patients would likely receive benefit from this operation, thus justifying the morbidity risk, future studies are needed to characterize this most at-risk group. Before this, however, given the shorter length of stay and fewer major complications observed, results of this novel study appear to suggest that supercharging anastomoses could become a standard part of the operation instead of being performed only selectively. The prospect of coupling the performance and esophagectomy without incurring the risk of an anastomotic complication may be the long sought after and celebrated icing on the cake. Perhaps someday this strategy will allow thoracic surgeons to have this cake and eat it too...with their patients, of course.

\section{References}

1. Zehetner J, DeMeester SR, Alicuben ET, Oh DS, Lipham JC, Hagen JA, et al. Intraoperative assessment of perfusion of the gastric graft and correlation with anastomotic leaks after esophagectomy. Ann Surg. 2015;262:74-8.

2. Lu M, Luketich JD, Levy RM, Awais O, Sarkaria I, Visintainer P, et al. Anastomotic complications after esophagectomy: influence of omentoplasty in propensity-weighted cohorts. J Thorac Cardiovasc Surg. 2020;159:2096-105.

3. Takeda FR, Tutihashi R, Tustumi F, Sallum RAA, de Freitas Busnardo F, Ribeiro U Jr et al. Supercharged cervical anastomosis for esophagectomy and gastric pull-up: a prospective comparative study. J Thorac Cardiovasc Surg. 2021;162:688-97.e3.
See Article page 688

\section{Commentary: Eliminating cervical anastomotic leak after esophagectomy: To supercharge or not to supercharge, that's the question}

\author{
Toni Lerut, $\mathrm{MD}, \mathrm{PhD}$
}

Anastomotic leaks have been and still are the Achilles heel of esophagectomy. When I started my career in the midseventies of the previous century, anastomotic leaks had a grim reputation because of their high associated mortality. An international multicenter report on 2400 esophagectomies published in 1980 revealed a 21\% mortality in cervical anastomotic leak. ${ }^{1}$ Over time, this mortality has decreased to become an exception nowadays. However, the incidence of leaks still remains high, alarmingly high.

The Esophageal Complications Consensus Group, involving a worldwide platform of 24 high-volume esophageal surgical centers in 14 countries, analyzed 2704

\footnotetext{
From the Department of Thoracic Surgery, University Hospitals Leuven, Leuven, Belgium.

Disclosures: The author reported no conflicts of interest.

The Journal policy requires editors and reviewers to disclose conflicts of interest and to decline handling or reviewing manuscripts for which they may have a conflict of interest. The editors and reviewers of this article have no conflicts of interest.

Received for publication June 26, 2020; revisions received June 26, 2020; accepted for publication June 26, 2020; available ahead of print July 14, 2020.

Address for reprints: Toni Lerut, MD, PhD, Kortrijksestraat 191, 3010 Kessel Lo,

Belgium (E-mail: toni.lerut@kuleuven.be).

J Thorac Cardiovasc Surg 2021;162:699-700

$0022-5223 / \$ 36.00$

Copyright (c) 2020 by The American Association for Thoracic Surgery

https://doi.org/10.1016/j.jtcvs.2020.06.102
}

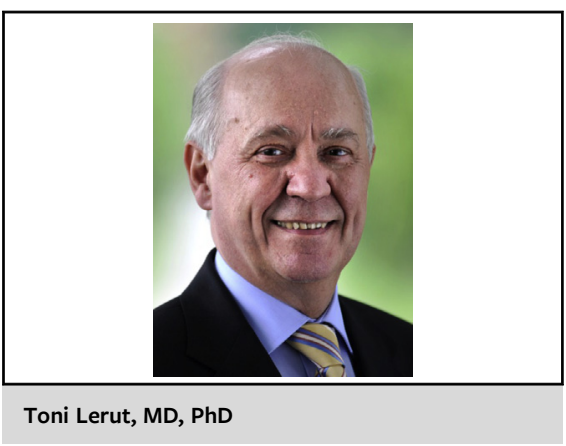

CENTRAL MESSAGE

Cervical anastomotic leak rate has not decreased over time and remains far too high. Supercharged esophagogastrostomy has promising potential in selected patients.

esophagectomies between 2015 and 2016, reporting $11.4 \%$ anastomotic leaks. ${ }^{2} \mathrm{~A}$ sobering fact check: this is almost identical to the $12 \%$ overall leak rate in the 1980 report! It's an inconvenient truth because leaks cause shortand long-term patient morbidity, quality of life impairment, financial costs, and possible legal consequences.

Decrease of arterial inflow and venous outflow congestion at the distal end of the conduit are considered to be the culprits. Surgeons have relentlessly tried to get a better grip on this cumbersome complication. Delicate handling of tissues at the distal end of the conduit, shortening of the distal end of the gastric tube in the neck whenever possible, avoiding traction on the conduit and anastomosis, and using 